\title{
Reliable and Damage-Free Estimation of Resistivity of ZnO Thin Films for Photovoltaic Applications Using Photoluminescence Technique
}

\author{
N. Poornima, T. V. Vimalkumar, V. G. Rajeshmon, C. Sudha Kartha, and K. P. Vijayakumar \\ Department of Physics, Cochin University of Science and Technology, Cochin, Kerala 682022, India \\ Correspondence should be addressed to K. P. Vijayakumar; kpv@cusat.ac.in
}

Received 9 November 2012; Revised 1 January 2013; Accepted 6 January 2013

Academic Editor: Mahmoud M. El-Nahass

Copyright (C) 2013 N. Poornima et al. This is an open access article distributed under the Creative Commons Attribution License, which permits unrestricted use, distribution, and reproduction in any medium, provided the original work is properly cited.

\begin{abstract}
This work projects photoluminescence (PL) as an alternative technique to estimate the order of resistivity of zinc oxide ( $\mathrm{ZnO}$ ) thin films. $\mathrm{ZnO}$ thin films, deposited using chemical spray pyrolysis (CSP) by varying the deposition parameters like solvent, spray rate, $\mathrm{pH}$ of precursor, and so forth, have been used for this study. Variation in the deposition conditions has tremendous impact on the luminescence properties as well as resistivity. Two emissions could be recorded for all samples-the near band edge emission (NBE) at $380 \mathrm{~nm}$ and the deep level emission (DLE) at $\sim 500 \mathrm{~nm}$ which are competing in nature. It is observed that the ratio of intensities of DLE to NBE $\left(I_{\mathrm{DLE}} / I_{\mathrm{NBE}}\right)$ can be reduced by controlling oxygen incorporation in the sample. $I-V$ measurements indicate that restricting oxygen incorporation reduces resistivity considerably. Variation of $I_{\mathrm{DLE}} / I_{\mathrm{NBE}}$ and resistivity for samples prepared under different deposition conditions is similar in nature. $I_{\mathrm{DLE}} / I_{\mathrm{NBE}}$ was always less than resistivity by an order for all samples. Thus from PL measurements alone, the order of resistivity of the samples can be estimated.
\end{abstract}

\section{Introduction}

Extensive research is being promoted on $\mathrm{ZnO}$ owing to the unique optoelectronic properties such as wide band gap of $3.3 \mathrm{eV}$, large room-temperature exciton binding energy of $60 \mathrm{meV}$, and piezoelectricity [1-5]. The wide band gap makes it an excellent candidate for use in UV sensors [6], light emitting diodes [7, 8], solar cells [9-11], and so forth. It serves its purpose as antireflection coating in solar cells [12] and nanorod layers of $\mathrm{ZnO}$ can be coupled with compound semiconductor absorber layers as in extremely thin absorber (ETA) cells [13-15] or can be used in organic photovoltaics $[16,17]$.

A wide range of deposition techniques have been reported for $\mathrm{ZnO}$ [18-35]. For device applications, films with good optical quality are required on a large scale. This is where costeffective deposition techniques as wet chemical methods and spray pyrolysis play a vital role $[36,37]$. We fabricated $\mathrm{ZnO}$ thin films using the chemical spray pyrolysis (CSP) technique with an intention to develop them as an affordable substitute to ITO. The focus of the industry is mainly on developing cost-effective deposition as well as characterization techniques so that the end product is consumer friendly. In the present work, with the method for depositing TCO being CSP, the requirement for cost-effective technique is fulfilled. $\mathrm{ZnO}$ is a candidate which exhibits strong excitonic as well as defect-assisted luminescence. Any change in composition by varying the stoichiometry, incorporating dopants, and varying the deposition parameters can cause variation in the PL spectrum. Electrical properties, mainly the resistivity, can be varied desirably by bringing about such variations. Many groups have come up with the observation that PL can be used to relate to the electrical properties $[38,39]$. Our group also has reported such an observation on SnS thin films [40].

Thin films of $\mathrm{ZnO}$ were deposited by spraying alcoholic solution of zinc salt and various parameters such as spray rate, solvent used, $\mathrm{pH}$ of solution, and dopants used were varied; its effect on PL spectrum and resistivity was analyzed. In order to substantiate our findings that PL can be used to analyze the resistivity of $\mathrm{ZnO}$ thin films, we have also included our own similar observations with indium sulphide $\left(\mathrm{In}_{2} \mathrm{~S}_{3}\right)$ thin films. 


\section{Experimental Technique}

$\mathrm{ZnO}$ thin films were deposited on soda lime glass substrates maintained at $450^{\circ} \mathrm{C}$ by spraying $0.3 \mathrm{M}$ solution of zinc acetate dissolved in a mixture of alcohol and water. We had already reported the effectiveness of employing postdeposition treatment (inversion) on improving the resistivity of $\mathrm{ZnO}$ thin films by two orders [41]. Hence all the samples prepared were given this inversion treatment in order to have the added benefit of the treatment in addition to the variation in deposition parameters themselves. The alphabet letter "I" has been included in all the sample names to indicate that the samples have been subjected to "inversion process." Initially films were prepared using both "propanol-water mixture" and "ethanol-water mixture" as a base solvent. Films prepared with propanol-water mixture as a solvent were named ZP-I and those prepared with ethanol-water mixture as a solvent were named ZE-I. Alcohol-to-water ratio in the solvent is an important parameter. After identifying propanol as the better solvent, films were prepared for different propanolto-water ratios, namely, $0.25: 1,0.42: 1,1: 1,1.5: 1$, and $2.3: 1$, and these were named ZP0.25:1-I, ZP0.42:1-I, and so forth. With the optimum propanol-to-water ratio in the solvent, $\mathrm{pH}$ of the spray solution was varied from 3 to 6 . Films prepared were named as 3-I, 4-I, 5-I, and 6-I for simplicity. By fixing the propanol-to-water ratio and $\mathrm{pH}$ at the optimum value, films were prepared for three different spray rates-3, 7, and $10 \mathrm{~mL} / \mathrm{min}$, which were named as Z3-I, Z7-I, and Z10-I, respectively. With the main motivation being bringing down the resistivity of $\mathrm{ZnO}$ for $\mathrm{TCO}$ applications, doping with indium was tried and samples were prepared with various doping percentages of indium after optimizing all other deposition parameters. These were named as Z0.5In-I, Z1InI, Z1.5In-I, Z2In-I, and Z2.5In-I, respectively, based on the doping percentages of indium. PL measurements were done on all samples prepared. The output of He-Cd laser (Kimmon Koha Co., Ltd.) at $325 \mathrm{~nm}$ was used as the excitation source and the emission spectrum was recorded using USB2000 Ocean Optics spectrophotometer coupled to the computer via the custom-made software OOIbase 32 . Thickness of all samples was measured using Dektak 6M stylus profiler. Resistivity of the samples was obtained from "two probe" $I$ $V$ measurements using Keithley 236 Source Measure Unit. For resistivity measurements, ohmic contacts of dimension $5 \mathrm{~mm} \times 1 \mathrm{~mm}$ using silver paint were given on the sample. The correlation observed between PL measurements and resistivity of the samples has been explained in subsequent sections.

\section{Results and Discussion}

The room-temperature PL spectrum of $\mathrm{ZnO}$ has two bandsthe near band edge emission (NBE) arising out of the recombination of bound excitons and the deep level emission (DLE). The origin of DLE is still being debated over; many have attributed the emission as arising due to oxygen vacancies, zinc interstitials, and so forth [42-44], while others have related this emission to the $\mathrm{O}_{\mathrm{Zn}}$ antisite defect $[45,46]$. The effect of doping various transition metals on the broad defectrelated luminescence of $\mathrm{ZnO}$ has also been reported [47]. Studies on the behavioural patterns of defects with excitation power are also reported. For systems with excellent optical quality, NBE is prominent whereas when the defect concentration is high, DLE gains prominence [48]. It has been generally observed that when the metal-to-oxygen ratio is high, the NBE gains strength. The effect of various treatments on PL spectrum has been described in subsequent sections. For all our samples, we could observe two emissions-the NBE and the DLE centered in the blue green. Assigning the emission as a transition from conduction band to antisite oxygen has been substantiated using irradiation studies on $\mathrm{ZnO}$ [49].

We begin our discussion by throwing light on the postdeposition treatment that we have given to all films. Still now there is not much consensus and understanding on the formation and annihilation of point defects on annealing. Any postdeposition treatment given definitely affects the extent of oxygen incorporation and it can be observed that there is an interesting correlation between the extent of oxygen incorporation, PL spectrum, and resistivity. Figure 1(a) depicts the variation of the PL spectrum for various treatments given to the sample. For convenience, samples left to cool on their own after deposition have been named ZR and samples which were subjected to the postdeposition treatment have been named ZI. We have presented the results on ZI, ZR, ZI-v (sample subjected to vacuum annealing after giving postdeposition treatment), and ZI-va (ZI-v subjected to air annealing) in Figure 1(a).

The reduction in oxygen incorporation results in reduction of the defect $\mathrm{O}_{\mathrm{Zn}}$ antisite, resulting in reduction of the intensity of DLE. Upon postdeposition treatment, the $\mathrm{Zn} / \mathrm{O}$ ratio increases (which has been verified using XPS and has already been reported [41]) and the intensity of NBE increases. The resistivity is also reduced by two orders. Results from XPS studies complement those from PL and rightly indicate that PL can also be used for an indirect analysis of composition. ZI was subjected to vacuum annealing and the vacuum annealed sample was subjected to air annealing solely to confirm that oxygen was the factor that decides the intensity of DLE as well as the resistivity. It can be seen that for samples of ZI-v, the fine structure of NBE appears which indicates the enhanced crystallinity of the sample. Resistivity is lowered further by an order. For samples of ZI-va, NBE has broadened and the intensity of DLE has increased. Resistivity has gone up by an order on air annealing. We observe that there is a relation between the ratio of intensities of DLE to $\operatorname{NBE}\left(I_{\mathrm{DLE}} / I_{\mathrm{NBE}}\right)$ and the resistivity. The smaller the ratio, the lower the resistivity (or the better the conductivity) and vice versa. The ratio $I_{\mathrm{DLE}} / I_{\mathrm{NBE}}$ is a measure of the concentration of the defects present in the sample. Thus the choice of this ratio as an indicator of sample quality can be justified. Figure 1(b) represents the effect of postdeposition treatment on $I_{\mathrm{DLE}} / I_{\mathrm{NBE}}$ and resistivity. The graph has been plotted on a log scale so that the variation can be clearly understood. It can be seen from the graph that the minimum value for both $I_{\mathrm{DLE}} / I_{\mathrm{NBE}}$ and resistivity is for sample of ZI-v and the variation of the two parameters is similar. 


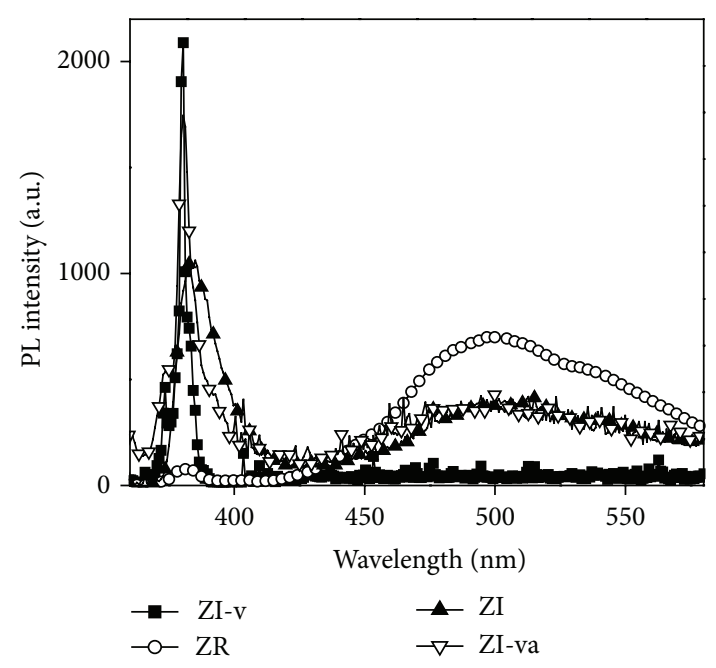

(a)

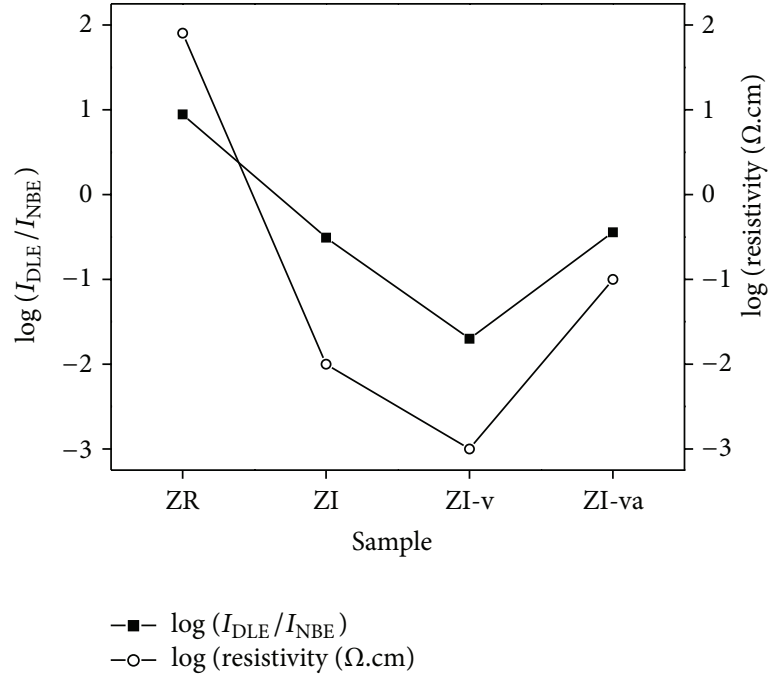

(b)

FIgUre 1: (a) PL spectrum of samples ZR, ZI, ZI-v, and ZI-va. (b) Variation of $I_{\mathrm{DLE}} / I_{\mathrm{NBE}}$ and resistivity for various treatments to a sample.

\subsection{Effect of Variation of Deposition Parameters}

3.1.1. Effect of Solvent Variation on PL Spectrum. Transparency of the films was not good and resistivity was also high for films prepared using distilled water as a solvent. The effect of different alcoholic medium on obtaining crystalline transparent $\mathrm{ZnO}$ has also been an area of interest to many [50]. The benefit of using alcoholic solution in obtaining homogeneous films as well as clearly defined nanostructures has already been reported by many groups [51]. In order to improve the optical quality of the films, alcohol-water mixture was opted as a solvent.

The effect of using two different types of alcoholic solutions on the PL spectrum of $\mathrm{ZnO}$ thin films is shown in Figure 2.

It can be seen that for ZP-I, NBE is much enhanced in intensity and the ratio of $I_{\mathrm{DLE}} / I_{\mathrm{NBE}}$ is smaller when compared to ZE-I. The defect concentration is higher in ZE-I. The high vapour pressure of alcohol helps in the formation of a uniform spray cone of finer droplets [52]. With alcohol being highly volatile, it escapes easily once it falls on the heated substrate. The lower $I_{\mathrm{DLE}} / I_{\mathrm{NBE}}$ ratio as well as the lower resistivity indicates that propanol is better than ethanol. The variation in $I_{\mathrm{DLE}} / I_{\mathrm{NBE}}$ and resistivity of $\mathrm{ZnO}$ thin films for different propanol-to-water ratios in the solvent was studied and has been plotted in Figure 3(a).

Resistivity is lowest $\left[2.5 \times 10^{-2} \Omega \cdot \mathrm{cm}\right]$ for a propanol-towater ratio of $1: 1$. Here also we observe that the variation of $I_{\mathrm{DLE}} / I_{\mathrm{NBE}}$ for all samples matches closely with the variation of resistivity. Supporting evidence from structural, optical, and electrical studies, and so forth has been reported elsewhere [53].

3.1.2. Effect of Variation of Spray Solution pH on PL Spectrum. The effect of variation of $\mathrm{pH}$ of spray solution on the $\mathrm{PL}$ spectrum is shown in Figure 4.

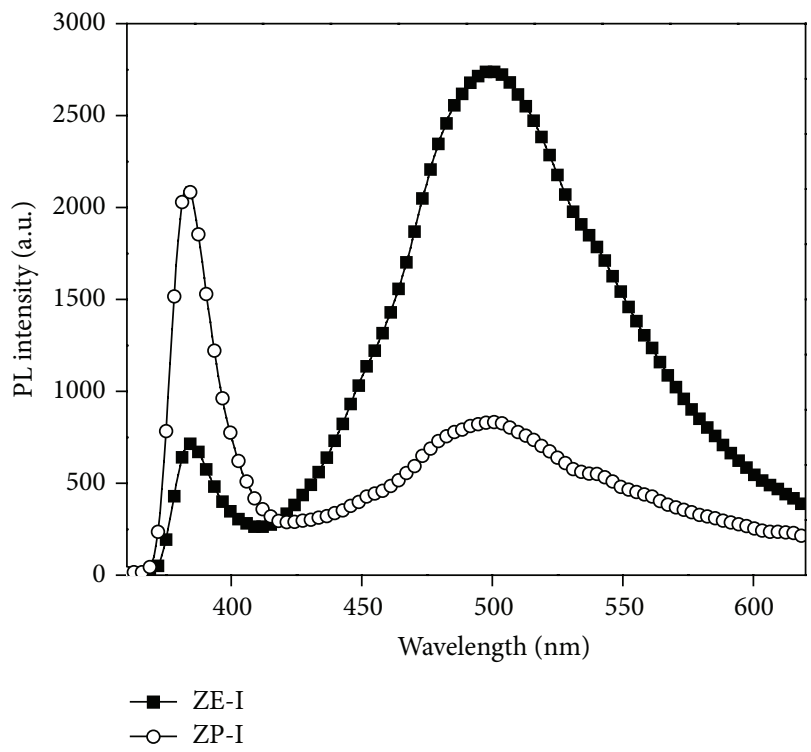

FIgURE 2: PL spectrum of ZP-I (propanol-based films) and ZE-I (ethanol-based films).

$\mathrm{pH}$ control was attained by adding a few drops of acetic acid to the precursor solution. This also inhibits hydroxide formation. Acetic acid is not added at all in sample 6-I ( $\mathrm{pH}$ of spray solution $=6$ ), and in sample 4 -I a few drops of acetic acid has been added so as to make the $\mathrm{pH}$ of the spray solution equal to $4 \mathrm{pH}$ determines the complexes formed at the beginning of the reaction, the enhancement in crystallinity, morphology, and so forth of the films formed [54].

We have observed that films with excellent optical (maximum transmittance) and electrical (lowest resistivity) properties were obtained when the spray solution was acidic $(\mathrm{pH}=4)$. The variation of $I_{\mathrm{DLE}} / I_{\mathrm{NBE}}$ and resistivity is plotted 


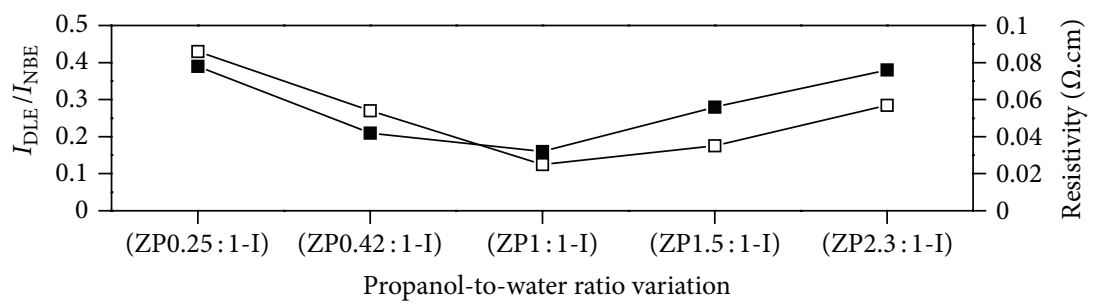

(a)

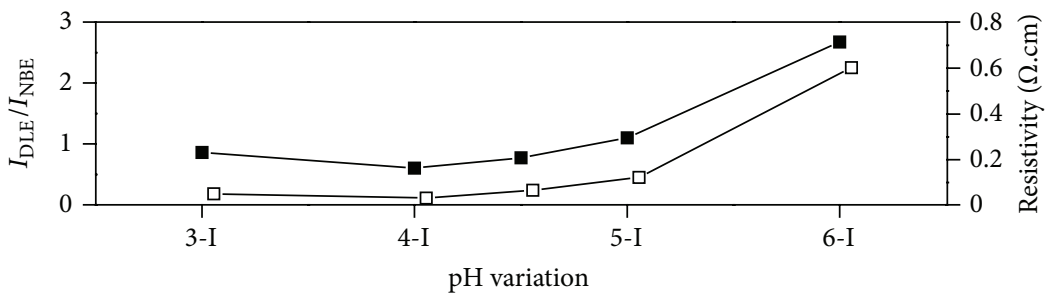

(b)

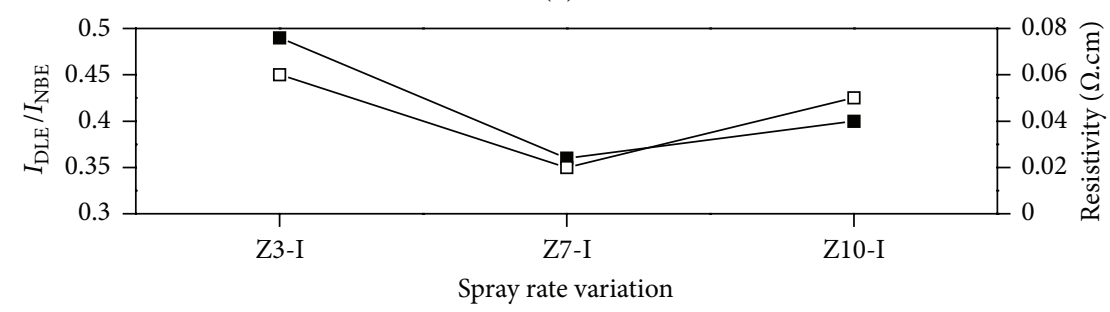

(c)

FIGURE 3: Variation of $I_{\mathrm{DLE}} / I_{\mathrm{NBE}}$ and resistivity for (a) different propanol-to-water ratios in the solvent, (b) various pH of spray solution, and (c) different spray rates.

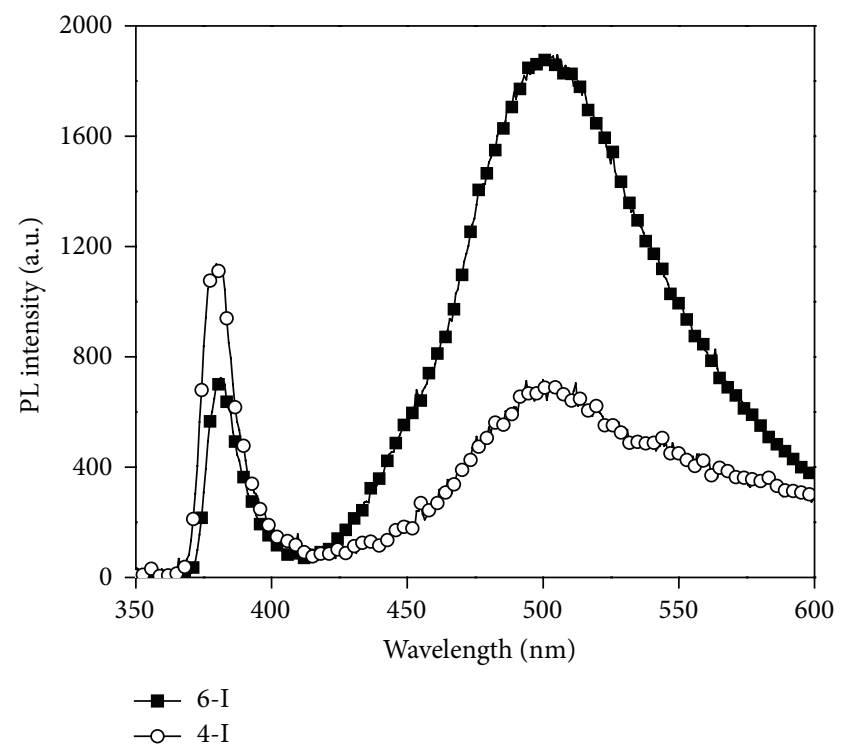

Figure 4: PL spectrum of $\mathrm{ZnO}$ thin films prepared using a spray solution of different $\mathrm{pH}$.

in Figure 3(b). They show a similar variation and least values for both have been obtained when the $\mathrm{pH}$ of spray solution is maintained at 4 . It has been well studied that $\mathrm{pH}$ determines the route of the reaction by controlling the intermediates formed as well as the rate of the reaction. Acidic $\mathrm{pH}$ favours $\mathrm{Zn}^{2+}$ ion formation which in turn facilitates $\mathrm{ZnO}$ formation. At $\mathrm{pH}$ other than 4 , there might be unreacting intermediates which tend to deteriorate the properties of the film.

3.1.3. Effect of Spray Rate on PL Spectrum. In spray deposition, the solution in the form of fine droplets falls on the preheated substrate and the desired compound forms on the substrate. The droplets that strike the substrate initiate the formation of disk-shaped structures which later coalesce and form a continuous film. The continuity and roughness of the film depend largely on the spray rate. Figure 5(a) depicts the effect of spray rate on the PL spectrum and Figure 3(c) depicts its effect on the ratio of $I_{\mathrm{DLE}} / I_{\mathrm{NBE}}$ and the resistivity. It can be observed that the ratio as well as the resistivity is minimum for Z7-I.

The full width at the half maximum (FWHM) of NBE is minimum and the intensity is the maximum when spray rate is $7 \mathrm{~mL} / \mathrm{min}$ as opposed to 3 and $10 \mathrm{~mL} / \mathrm{min}$. Such low values of FWHM and intense NBE peak indicate the fine optical quality of the prepared films. In addition to finding out the ratio of $I_{\mathrm{DLE}} / I_{\mathrm{NBE}}$, the FWHM of the NBE peak at $3.26 \mathrm{eV}$ was also found out which is another strong indicator of crystalline 


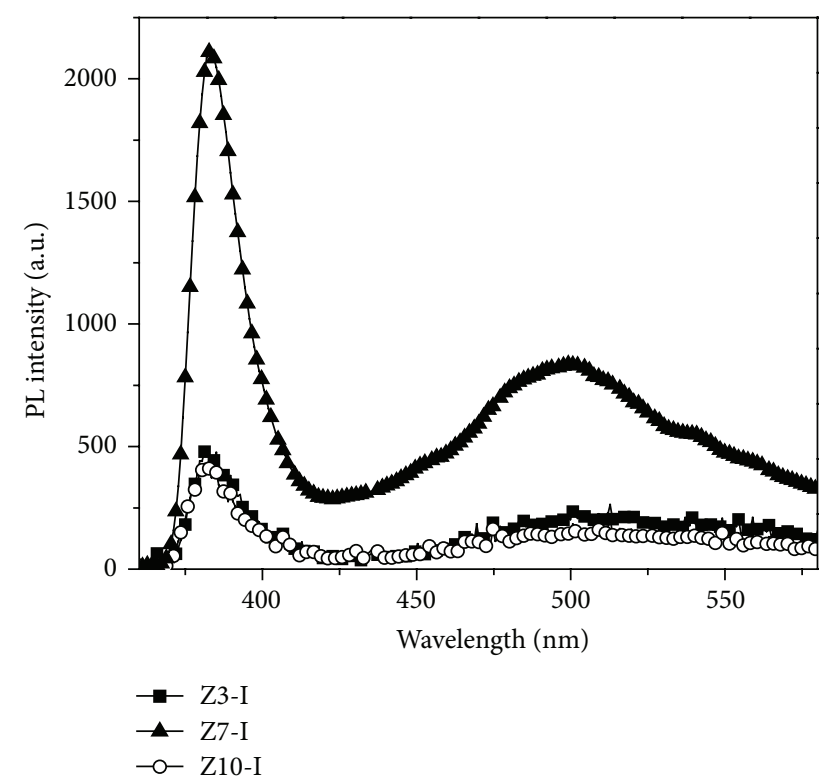

(a)

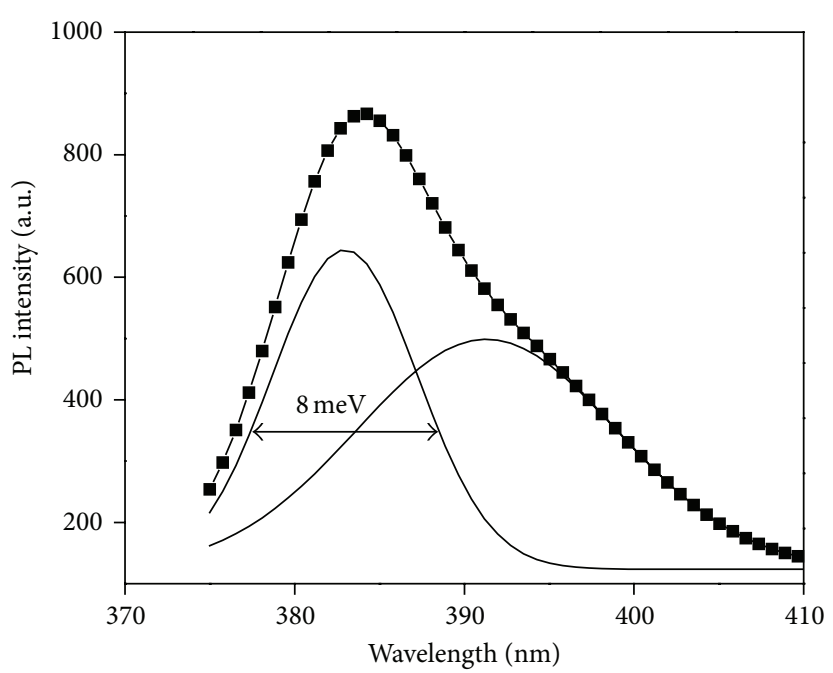

(b)

Figure 5: (a) PL spectrum of ZnO thin films prepared at different spray rates. (b) Gaussian fitting and FWHM of the NBE peak at $3.26 \mathrm{eV}$.

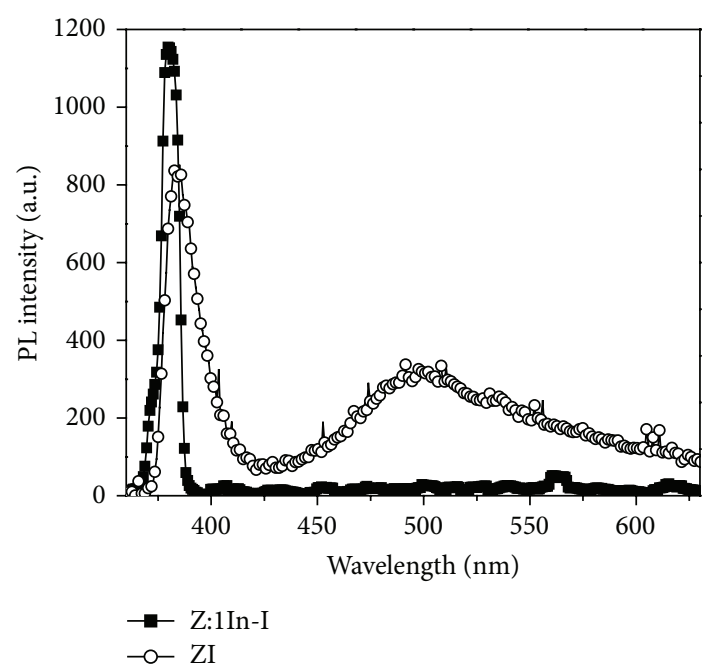

(a)

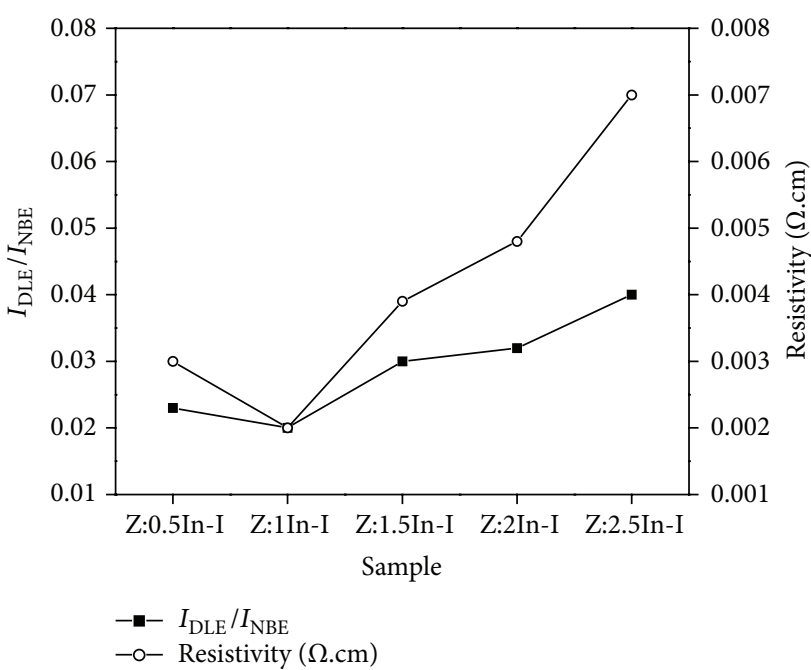

(b)

FIGURE 6: (a) Effect of indium doping on ZnO thin films. (b) Variation of $I_{\mathrm{DLE}} / I_{\mathrm{NBE}}$ and resistivity with indium doping in ZnO thin films.

quality of the material. It could be observed that for films prepared at $7 \mathrm{~mL} / \mathrm{min}$, using a propanol-based precursor solution of $\mathrm{pH} 4$ and given a postdeposition treatment, the FWHM of NBE was the least ( $\approx 8 \mathrm{meV}$ ) (Figure 5(b)).

3.2. Effect of Indium Doping on the PL Spectrum. With all the deposition conditions being optimized, the next step for reducing the resistivity was by doping with a trivalent metal. The effect of indium doping on the PL spectrum of $\mathrm{ZnO}$ is shown in Figure 6(a).

It can be seen that DLE is quite subdued for indiumincorporated films and the ratio of $I_{\mathrm{DLE}} / I_{\mathrm{NBE}}$ has been observed to be the least for $\mathrm{ZnO}: 1 \mathrm{In}$. Electrical measurements indicate that resistivity is also minimum for $\mathrm{ZnO}: 1 \mathrm{In}$. The reason for reduction in resistivity may be because when indium is introduced into $\mathrm{ZnO}$ thin films, it accommodates itself in vacant $\mathrm{Zn}$ lattice sites thereby reducing the probability of oxygen occupying zinc site. This argument can be justified as the ionic radii of $\mathrm{Zn}^{2+}$ and $\mathrm{In}^{3+}$ are close-lying (0.74 and $0.75 \AA$, resp.), which in turn reduces the concentration of $\mathrm{O}_{\mathrm{Zn}}$ antisite defect centres which explains the reduction in intensity of DLE and thereby the ratio $I_{\mathrm{DLE}} / I_{\mathrm{NBE}}$. But this process cannot take place indefinitely. So beyond a particular quantity of indium incorporated, the resistivity starts 


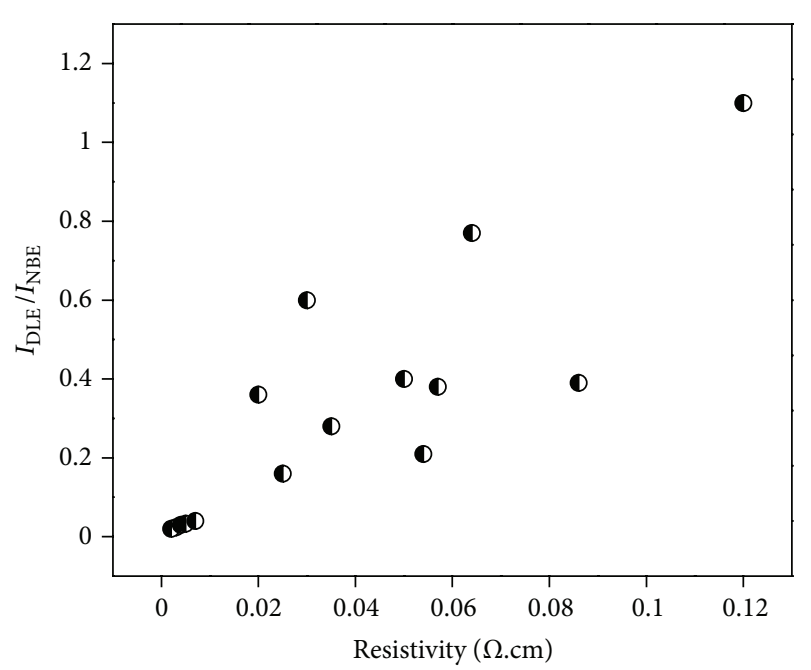

FIGURE 7: Variation of $I_{\mathrm{DLE}} / I_{\mathrm{NBE}}$ as a function of resistivity for all $\mathrm{ZnO}$ samples chosen for study.

increasing. This might be due to scattering of carriers from excess indium occupying sites other than lattice positions [55]. Figure 6(b) depicts the effect of indium doping on $I_{\mathrm{DLE}} / I_{\mathrm{NBE}}$ and resistivity.

Based on our discussion in the previous sections, variation of $I_{\mathrm{DLE}} / I_{\mathrm{NBE}}$ with resistivity has been plotted (Figure 7 ) in order to analyze the correlation between the two parameters.

The extent of correlation is usually expressed in terms of "correlation coefficient." Generally, if the two parameters are perfectly correlated, the correlation coefficient assumes the value 1 . For perfectly uncorrelated data, it is zero. Another point to note is whether the parameters are positively or negatively correlated. We say that two parameters are positively correlated when both parameters exhibit a similar trend in variation, that is, when one parameter is high, if the other is also high and vice versa. For perfect positive correlation, the plot would be linear with positive slope. From our observations, resistivity and $I_{\mathrm{DLE}} / I_{\mathrm{NBE}}$ exhibit positive correlation and the correlation coefficient was found to be 0.844 . This is a reasonably good value for the correlation coefficient. From our observations, we arrive at an empirical relation between the order of resistivity $(Y)$ and the order of $I_{\mathrm{DLE}} / I_{\mathrm{NBE}}(X)$ as $Y=10^{-1} X$, which holds true for all the $\mathrm{ZnO}$ samples we have tried so far.

In order to substantiate the results on $\mathrm{ZnO}$, we performed a trial to check whether PL can be used to qualitatively analyze the resistivity of samples by conducting PL studies on spraydeposited $\mathrm{In}_{2} \mathrm{~S}_{3}$ thin films. $\operatorname{In}_{2} \mathrm{~S}_{3}$ thin films were prepared by spraying a solution containing indium chloride and thiourea in the ratio $1.2: 12$ at a spray rate of $6 \mathrm{~mL} / \mathrm{min}$ onto a substrate maintained at $350^{\circ} \mathrm{C}$. By birth, $\operatorname{In}_{2} \mathrm{~S}_{3}$ is formed with a large number of vacancies ordering at tetrahedral sites [56] and is also highly resistive (as-deposited films had resistivity of $2.3 \times$ $10^{5} \Omega \cdot \mathrm{cm}$ ). To bring down the resistivity for certain specific applications, we diffused the metal indium into as-deposited $\mathrm{In}_{2} \mathrm{~S}_{3}$ thin films. Different quantities of indium were diffused

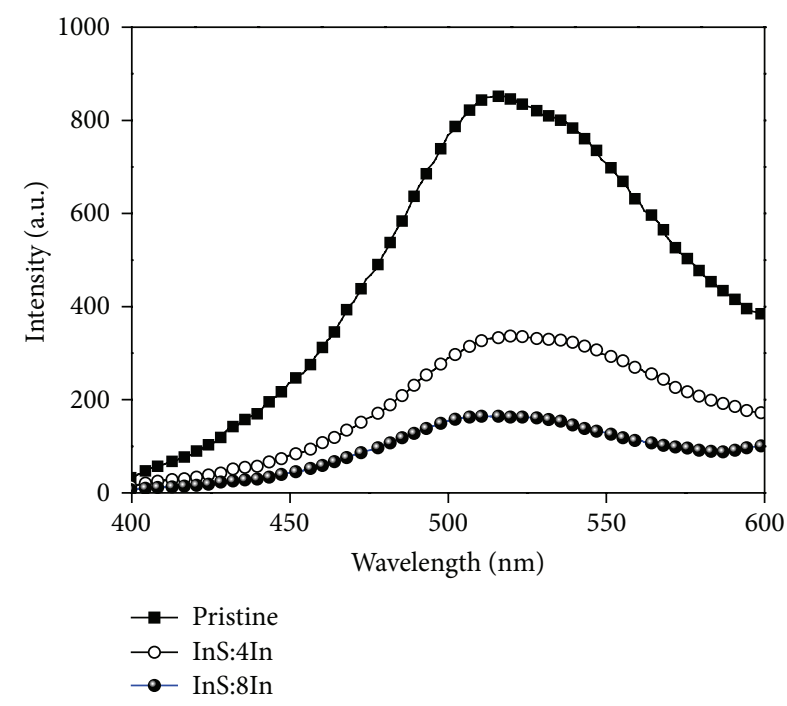

(a)

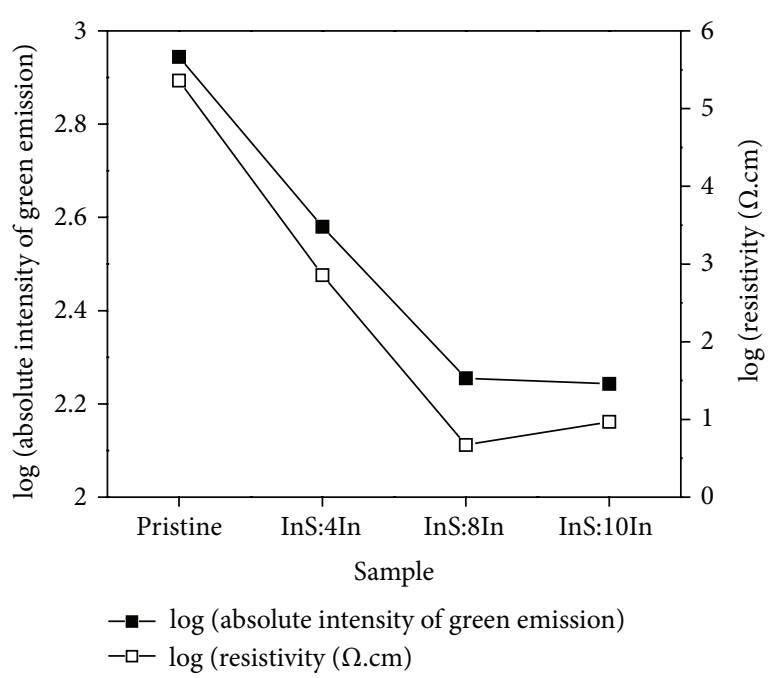

(b)

FIGURE 8: (a) Variation in intensity of green emission in the PL spectrum of $\operatorname{In}_{2} \mathrm{~S}_{3}$ thin films on indium incorporation. (b) Variation of absolute intensity of green emission and resistivity of $\operatorname{In}_{2} \mathrm{~S}_{3}$ thin films on indium incorporation drawn in a log scale.

by vacuum evaporation followed by subsequent annealing and samples were named as InS : 4In, InS : $6 \operatorname{In}$, InS : 8In, and InS : 10In, respectively. With indium diffusion, the resistivity of the samples could be reduced by five orders $(4.7 \Omega \cdot \mathrm{cm}$ for InS: 8In). The PL spectrum of $\operatorname{In}_{2} \mathrm{~S}_{3}$ is comprised of a green band (arising from $V_{\mathrm{S}}-V_{\text {In }}$ transition) and a red band (arising from $\mathrm{In}_{i}-\mathrm{O}_{\mathrm{Vs}}$ transition) [57]. The green emission in the PL spectrum is focussed in Figure 8(a). The diffused "In" occupies the vacant indium sites, which reduces the density of states of the defect $V_{\text {In }}$ which explains the drastic reduction in the intensity of green emission. "In" incorporation reduces the resistivity by lowering the scattering of carriers from defects.

The variation of absolute intensity of GB in the PL spectrum and resistivity of the films on indium incorporation 
has been depicted in Figure 8(b). It can be seen that the variation of both parameters follows a similar pattern.

Though we could not arrive at an empirical relation connecting PL and resistivity for $\operatorname{In}_{2} S_{3}$, the results on $\operatorname{In}_{2} S_{3}$ complement our observations on $\mathrm{ZnO}$ thin films. From our results on $\mathrm{ZnO}$ as well as $\mathrm{In}_{2} \mathrm{~S}_{3}$ thin films, it is clear that any manipulation of deposition parameters, stoichiometry, or doping to enhance the conductivity is reflected clearly in the PL spectrum and it is possible to assess the electrical properties using PL.

\section{Conclusion}

The major success of this work lies in asserting PL as the best available tool for damage-free analysis of the sample. We have been able to establish the direct connection of resistivity with the luminescence properties of $\mathrm{ZnO}$ thin films prepared by varying different deposition conditions. Using the empirical relation that we have proposed connecting the order of resistivity and the order of $I_{\mathrm{DLE}} / I_{\mathrm{NBE}}$, the idea of the order of resistivity can be estimated solely from PL measurements. This technique is of benefit to the industry as well as for analysis of samples as in situ nondestructive analysis on a large scale during processing is possible, employing PL.

\section{Conflict of Interests}

The authors of the paper do not have direct financial relation with any commercial identity mentioned in their paper that might lead to a conflict of interests for any of the authors.

\section{Acknowledgments}

N. Poornima is grateful to UGC for the fellowship under the UGC-RFSMS scheme. The authors are grateful to MNRE (Government of India), for many of the experimental setup.

\section{References}

[1] U. Özgür, Ya. I. Alimov, C. Liu et al., "A comprehensive review of $\mathrm{ZnO}$ materials and devices," Journal of Applied Physics, vol. 98, no. 4, Article ID 041301, 103 pages, 2005.

[2] M. Wraback, H. Shen, S. Liang, C. R. Gorla, and Y. Lu, "High contrast, ultrafast optically addressed ultraviolet light modulator based upon optical anisotropy in $\mathrm{ZnO}$ films grown on $\mathrm{R}-$ plane sapphire," Applied Physics Letters, vol. 74, no. 4, pp. 507509,1999

[3] D. C. Reynolds, D. C. Look, and B. Jogai, "Optically pumped ultraviolet lasing from $\mathrm{ZnO}$," Solid State Communications, vol. 99, no. 12, pp. 873-875, 1996.

[4] D. C. Look, C. Coşkun, B. Claflin, and G. C. Farlow, "Electrical and optical properties of defects and impurities in $\mathrm{ZnO}$," Physica B, vol. 340-342, pp. 32-38, 2003.

[5] T. T. Chen, C. L. Cheng, S. P. Fu, and Y. F. Chen, "Photoelastic effect in $\mathrm{ZnO}$ nanorods," Nanotechnology, vol. 18, no. 22, Article ID 225705, 4 pages, 2007.

[6] C. Jagadish and S. J. Pearton, Eds., ZnO Bulk, Thin Films and Nanostructures, Elsevier, Oxford, UK, 2006.
[7] R. Könenkamp, R. C. Word, and M. Godinez, "Ultraviolet electroluminescence from $\mathrm{ZnO}$ /polymer heterojunction lightemitting diodes," Nano Letters, vol. 5, no. 10, pp. 2005-2008, 2005.

[8] D. C. Kim, W. S. Han, H. K. Cho, B. H. Kong, and H. S. Kim, "Multidimensional $\mathrm{ZnO}$ light-emitting diode structures grown by metal organic chemical vapor deposition on p-Si," Applied Physics Letters, vol. 91, no. 23, Article ID 231901, 3 pages, 2007.

[9] P. Jackson, D. Hariskos, E. Lotter et al., "New world record efficiency for $\mathrm{Cu}(\mathrm{In}, \mathrm{Ga}) \mathrm{Se}_{2}$ thin-film solar cells beyond $20 \%$," Progress in Photovoltaics: Research and Applications, vol. 19, no. 7, pp. 894-897, 2011.

[10] A. Gupta and A. D. Compaan, "14\% CdS/CdTe thin film cells with ZnO:Al TCO," in Proceedings of the MRS Spring Meeting, pp. 1-6, San Francisco, Calif, USA, 2003, paper no. B3.9.

[11] U. Rau and M. Schmidt, "Electronic properties of ZnOCd$\mathrm{SCu}(\mathrm{In}, \mathrm{Ga}) \mathrm{Se}_{2}$ solar cells-aspects of heterojunction formation," Thin Solid Films, vol. 387, no. 1-2, pp. 141-146, 2001.

[12] J. Y. Chen and K. W. Sun, "Growth of vertically aligned $\mathrm{ZnO}$ nanorod arrays as antireflection layer on silicon solar cells," Solar Energy Materials and Solar Cells, vol. 94, no. 5, pp. 930934, 2010.

[13] R. Tena-Zaera, M. A. Ryan, A. Katty, G. Hodes, S. Bastide, and C. Lévy-Clément, "Fabrication and characterization of $\mathrm{ZnO}$ nanowires/CdSe/CuSCN eta-solar cell," Comptes Rendus Chimie, vol. 9, no. 5-6, pp. 717-729, 2006.

[14] M. Krunks, E. Kärber, A. Katerski et al., "Extremely thin absorber layer solar cells on zinc oxide nanorods by chemical spray," Solar Energy Materials and Solar Cells, vol. 94, no. 7, pp. 1191-1195, 2010.

[15] D. Kieven, T. Dittrich, A. Belaidi et al., "Effect of internal surface area on the performance of $\mathrm{ZnO} \mathrm{In}_{2} \mathrm{~S}_{3}$ CuSCN solar cells with extremely thin absorber," Applied Physics Letters, vol. 92, no. 15, Article ID 153107, 3 pages, 2008.

[16] W. J. E. Beek, L. H. Slooff, M. M. Wienk, J. M. Kroon, and R. A. J. Janssen, "Hybrid solar cells using a zinc oxide precursor and a conjugated polymer," Advanced Functional Materials, vol. 15, no. 10, pp. 1703-1707, 2005.

[17] W. J. E. Beek, M. M. Wienk, M. Kemerink, X. Yang, and R. A. J. Janssen, "Hybrid zinc oxide conjugated polymer bulk heterojunction solar cells," Journal of Physical Chemistry B, vol. 109, no. 19, pp. 9505-9516, 2005.

[18] J. S. Huang and C. F. Lin, "Influences of $\mathrm{ZnO}$ sol-gel thin film characteristics on $\mathrm{ZnO}$ nanowire arrays prepared at low temperature using all solution-based processing," Journal of Applied Physics, vol. 103, no. 1, Article ID 014304, 5 pages, 2008.

[19] D. Bera, L. Qian, S. Sabui, S. Santra, and P. H. Holloway, "Photoluminescence of $\mathrm{ZnO}$ quantum dots produced by a sol-gel process," Optical Materials, vol. 30, no. 8, pp. 1233-1239, 2008.

[20] T. Hiramatsu, M. Furuta, H. Furuta, T. Matsuda, and T. Hirao, "Influence of thermal annealing on microstructures of zinc oxide films deposited by RF magnetron sputtering," Japanese Journal of Applied Physics, vol. 46, no. 6A, pp. 3319-3323, 2007.

[21] J. Lu, Y. Zhang, Z. Ye, L. Wang, B. Zhao, and J. Huang, "p-type $\mathrm{ZnO}$ films deposited by DC reactive magnetron sputtering at different ammonia concentrations," Materials Letters, vol. 57, no. 22-23, pp. 3311-3314, 2003.

[22] E. S. Jung, J. Y. Lee, H. S. Kim, and N. W. Jang, "Structural and optical characteristics of $\mathrm{ZnO}$ films with oxygen content," Journal of the Korean Physical Society, vol. 47, no. 3, pp. S480S484, 2005. 
[23] H. Lin, S. Zhou, J. Zhou et al., "Structural and optical properties of a-plane $\mathrm{ZnO}$ thin films synthesized on $\gamma$ - $\mathrm{LiAlO}_{2}$ (302) substrates by low pressure metal-organic chemical vapor deposition," Thin Solid Films, vol. 516, no. 18, pp. 6079-6082, 2008.

[24] E. Guziewicz, I. A. Kowalik, M. Godlewski et al., "Extremely low temperature growth of $\mathrm{ZnO}$ by atomic layer deposition," Journal of Applied Physics, vol. 103, no. 3, Article ID 033515, 6 pages, 2008.

[25] A. Wójcik, M. Godlewski, E. Guziewicz, R. Minikayev, and W. Paszkowicz, "Controlling of preferential growth mode of $\mathrm{ZnO}$ thin films grown by atomic layer deposition," Journal of Crystal Growth, vol. 310, no. 2, pp. 284-289, 2008.

[26] E. Przeździecka, T. Krajewski, L. Wachnicki et al., "Characterization of $\mathrm{ZnO}$ films grown at low temperature," Acta Physica Polonica A, vol. 114, no. 5, pp. 1303-1310, 2008.

[27] K. Miyamoto, M. Sano, H. Kato, and T. Yao, "High-electronmobility $\mathrm{ZnO}$ epilayers grown by plasma-assisted molecular beam epitaxy," Journal of Crystal Growth, vol. 265, no. 1-2, pp. 34-40, 2004.

[28] S. H. Park, H. Suzuki, T. Minegishi et al., "Low-temperature growth of high-quality $\mathrm{ZnO}$ layers by surfactant-mediated molecular-beam epitaxy," Journal of Crystal Growth, vol. 309, no. 2, pp. 158-163, 2007.

[29] B. J. Norris, J. Anderson, J. F. Wager, and D. A. Keszler, "Spincoated zinc oxide transparent transistors," Journal of Physics D, vol. 36, no. 20, pp. L105-L107, 2003.

[30] P. F. Carcia, R. S. McLean, M. H. Reilly, and G. Nunes, “Transparent $\mathrm{ZnO}$ thin-film transistor fabricated by rf magnetron sputtering," Applied Physics Letters, vol. 82, no. 7, pp. 1117-1119, 2003.

[31] J. Siddiqui, E. Cagin, D. Chen, and J. D. Phillips, "ZnO thin-film transistors with polycrystalline (Ba,Sr) $\mathrm{TiO}_{3}$ gate insulators," Applied Physics Letters, vol. 88, no. 21, Article ID 212903, 3 pages, 2006.

[32] K. K. Kim, J. H. Song, H. J. Jung, W. K. Choi, S. J. Park, and J. H. Song, "The grain size effects on the photoluminescence of $\mathrm{ZnO} / \alpha-\mathrm{Al}_{2} \mathrm{O}_{3}$ grown by radio-frequency magnetron sputtering," Journal of Applied Physics, vol. 87, no. 7, pp. 3573-3575, 2000.

[33] P. Fons, K. Iwata, S. Niki, A. Yamada, and K. Matsubara, "Growth of high-quality epitaxial $\mathrm{ZnO}$ films on $\alpha-\mathrm{Al}_{2} \mathrm{O}_{3}$," Journal of Crystal Growth, vol. 201-202, pp. 627-632, 1999.

[34] Y. Liu, C. R. Gorla, S. Liang et al., "Ultraviolet detectors based on epitaxial $\mathrm{ZnO}$ films grown by MOCVD," Journal of Electronic Materials, vol. 29, no. 1, pp. 69-74, 2000.

[35] R. D. Vispute, V. Talyansky, S. Choopun et al., "Heteroepitaxy of $\mathrm{ZnO}$ on $\mathrm{GaN}$ and its implications for fabrication of hybrid optoelectronic devices," Applied Physics Letters, vol. 73, no. 3, pp. 348-350, 1998.

[36] V. V. Ursaki, I. M. Tiginyanu, V. V. Zalamai et al., "Photoluminescence of $\mathrm{ZnO}$ layers grown on opals by chemical deposition from zinc nitrate solution," Semiconductor Science and Technology, vol. 19, no. 7, pp. 851-854, 2004.

[37] K. Krunks, O. Bijakina, V. Mikli, T. Varema, and E. Mellikov, "Zinc oxide thin films by spray pyrolysis method," Physica Scripta, vol. 79, pp. 209-212, 1999.

[38] V. G. Rajeshmon, C. Sudha Kartha, K. P. Vijayakumar, C. Sanjeeviraja, T. Abe, and Y. Kashiwaba, "Role of precursor solution in controlling the opto-electronic properties of spray pyrolysed $\mathrm{Cu}_{2} \mathrm{ZnSnS}_{4}$ thin films," Solar Energy, vol. 85, no. 2, pp. 249-255, 2011.
[39] T. T. John, C. Sudha Kartha, K. P. Vijayakumar, T. Abe, and Y. Kashiwaba, "Preparation of indium sulfide thin films by spray pyrolysis using a new precursor indium nitrate," Applied Surface Science, vol. 252, no. 5, pp. 1360-1367, 2005.

[40] T. H. Sajeesh, C. Sudha Kartha, C. Sanjeeviraja, T. Abe, Y. Kashiwaba, and K. P. Vijayakumar, "Ex situ Sn diffusion: a wellsuited technique for enhancing the photovoltaic properties of a SnS absorber layer," Journal of Physics D, vol. 43, no. 44, Article ID 445102, 6 pages, 2010.

[41] T. V. Vimalkumar, N. Poornima, C. Sudha Kartha, K. P. Vijayakumar, T. Abe, and Y. Kashiwaba, "Enhancement of electrical conductivity in sprayed $\mathrm{ZnO}$ thin film through zeroenergyprocess," Physica B, vol. 405, no. 24, pp. 4957-4960, 2010.

[42] K. Vanheusden, W. L. Warren, C. H. Seager, D. R. Tallant, J. A. Voigt, and B. E. Gnade, "Mechanisms behind green photoluminescence in $\mathrm{ZnO}$ phosphor powders," Journal of Applied Physics, vol. 79, no. 10, pp. 7983-7990, 1996.

[43] F. A. Kroger, The Chemistry of Imperfect Crystals, NorthHolland, Amsterdam, The Netherlands, 1974.

[44] H. J. Egelhaaf and D. Oelkrug, "Luminescence and nonradiative deactivation of excited states involving oxygen defect centers in polycrystalline ZnO," Journal of Crystal Growth, vol. 161, no. 1-4, pp. 190-194, 1996.

[45] B. Lin, Z. Fu, Y. Jia, and G. Liao, "Defect photoluminescence of undoping $\mathrm{ZnO}$ films and its dependence on annealing conditions," Journal of the Electrochemical Society, vol. 148, no. 3, pp. G110-G113, 2001.

[46] P. M. Ratheesh Kumar, C. Sudha Kartha, K. P. Vijayakumar, F. Singh, and D. K. Avasthi, "Effect of fluorine doping on structural, electrical and optical properties of $\mathrm{ZnO}$ thin films," Materials Science and Engineering B, vol. 117, no. 3, pp. 307-312, 2005.

[47] C. Y. Lin, W. H. Wang, C. S. Lee, K. W. Sun, and Y. W. Suen, "Magnetophotoluminescence properties of Co-doped $\mathrm{ZnO}$ nanorods," Applied Physics Letters, vol. 94, no. 15, Article ID 151909, 3 pages, 2009.

[48] L. Kumari and W. Z. Li, "Synthesis, structure and optical properties of zinc oxide hexagonal microprisms," Crystal Research and Technology, vol. 45, no. 3, pp. 311-315, 2010.

[49] P. M. Ratheesh Kumar, K. P. Vijayakumar, and C. Sudha Kartha, "On the origin of blue-green luminescence in spray pyrolysed $\mathrm{ZnO}$ thin films," Journal of Materials Science, vol. 42, no. 8, pp. 2598-2602, 2007.

[50] A. Maldonado, M. D. L. Olvera, R. Asomoza, and S. TiradoGuerra, "Highly conductive and transparent in-doped zinc oxide thin films deposited by chemical spray using $\mathrm{Zn}\left(\mathrm{C}_{5} \mathrm{H}_{7} \mathrm{O}_{2}\right)_{2}$," Journal of Materials Science: Materials in Electronics, vol. 12, no. 11, pp. 623-627, 2001.

[51] J. S. Cho, S. K. Hong, D. S. Jung, and Y. C. Kang, "Effects of solvent on the properties of nano-sized glass powders prepared by flame spray pyrolysis," Journal of the Ceramic Society of Japan, vol. 116, no. 1350, pp. 334-340, 2008.

[52] E. Karber, T. Raadik, T. Dedova et al., "Photoluminescence of spray pyrolysis deposited ZnO nanorods," Nanoscale Research Letters, vol. 6, no. 1, article 359, pp. 1-7, 2011.

[53] T. V. Vimalkumar, N. Poornima, C. Sudha Kartha, and K. P. Vijayakumar, "Effect of precursor medium on structural, electrical and optical properties of sprayed polycrystalline $\mathrm{ZnO}$ thin films," Materials Science and Engineering B, vol. 175, no. 1, pp. 29-35, 2010.

[54] A. Maldonado, R. Asomoza, J. Cañetas-Ortega et al., "Effect of the $\mathrm{pH}$ on the physical properties of $\mathrm{ZnO}$ : in thin films 
deposited by spray pyrolysis," Solar Energy Materials and Solar Cells, vol. 57, no. 4, pp. 331-344, 1999.

[55] A. Maldonado, M. D. L. Olvera, R. Asomoza, and S. TiradoGuerra, "Highly conductive and transparent in-doped zinc oxide thin films deposited by chemical spray using $\mathrm{Zn}\left(\mathrm{C}_{5} \mathrm{H}_{7} \mathrm{O}_{2}\right)_{2}$," Journal of Materials Science: Materials in Electronics, vol. 12, no. 11, pp. 623-627, 2001.

[56] K. Kambas, J. Spyridelis, and M. Balkanski, "Far infrared and Raman optical study of $\alpha$ - and $\beta$ - $\mathrm{In}_{2} \mathrm{~S}_{3}$ compounds," Physica Status Solidi (B), vol. 105, no. 1, pp. 291-296, 1981.

[57] R. Jayakrishnan, T. T. John, C. Sudha Kartha, K. P. Vijayakumar, T. Abe, and Y. Kashiwaba, "Defect analysis of sprayed $\beta$-In2S3 thin films using photoluminescence studies," Semiconductor Science and Technology, vol. 20, no. 12, pp. 1162-1167, 2005. 

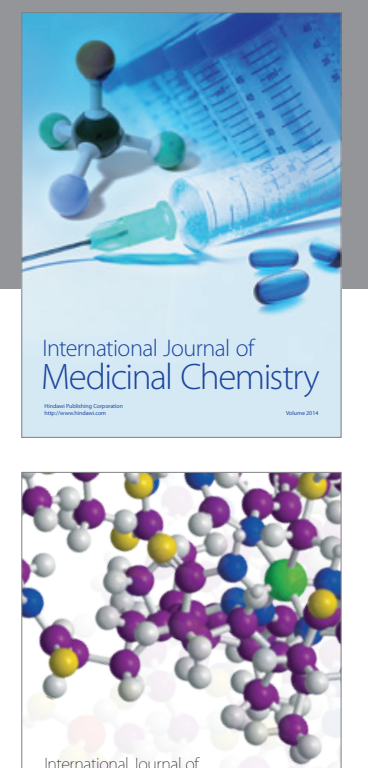

\section{Carbohydrate} Chemistry

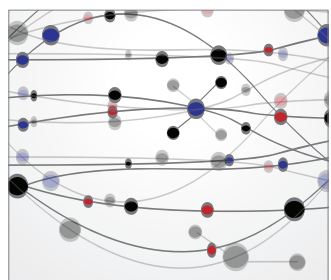

The Scientific World Journal
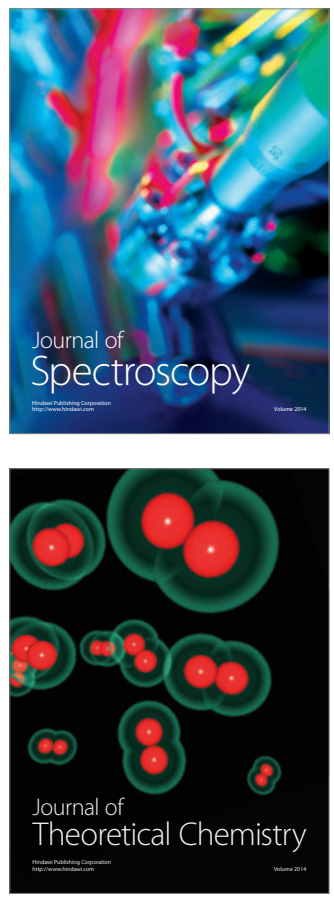
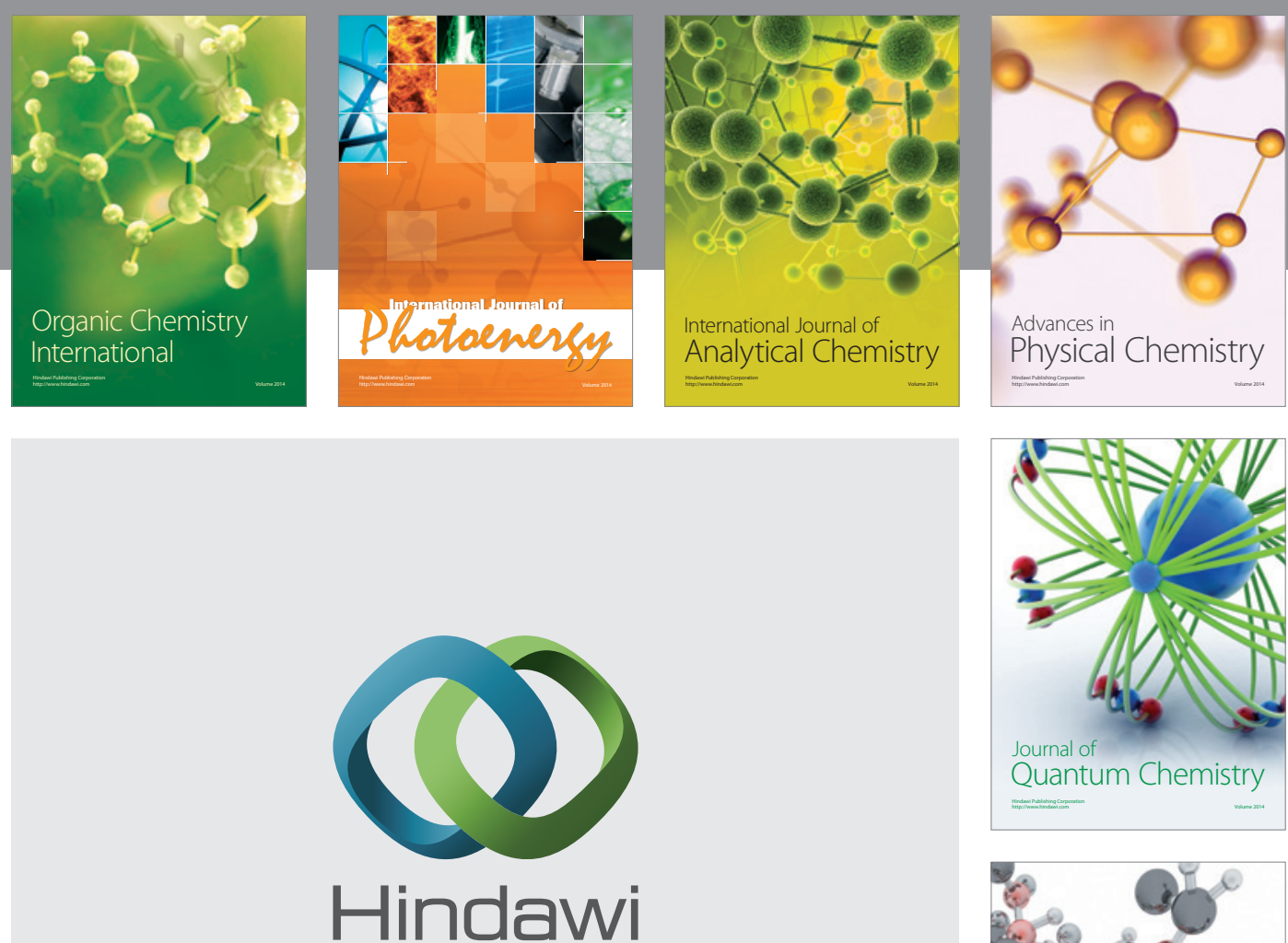

Submit your manuscripts at

http://www.hindawi.com

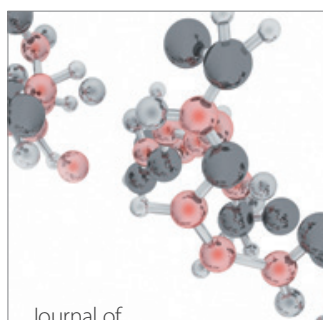

Analytical Methods

in Chemistry

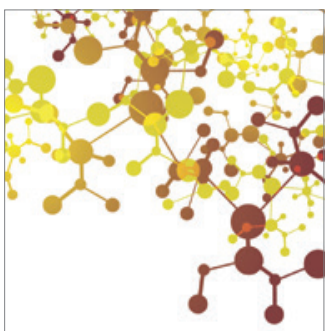

Journal of

Applied Chemistry

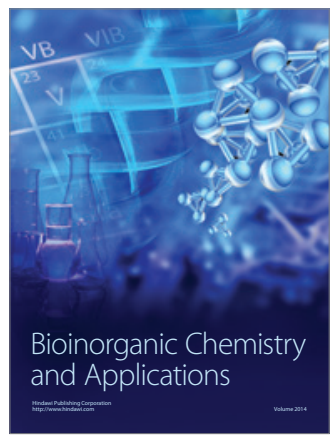

Inorganic Chemistry
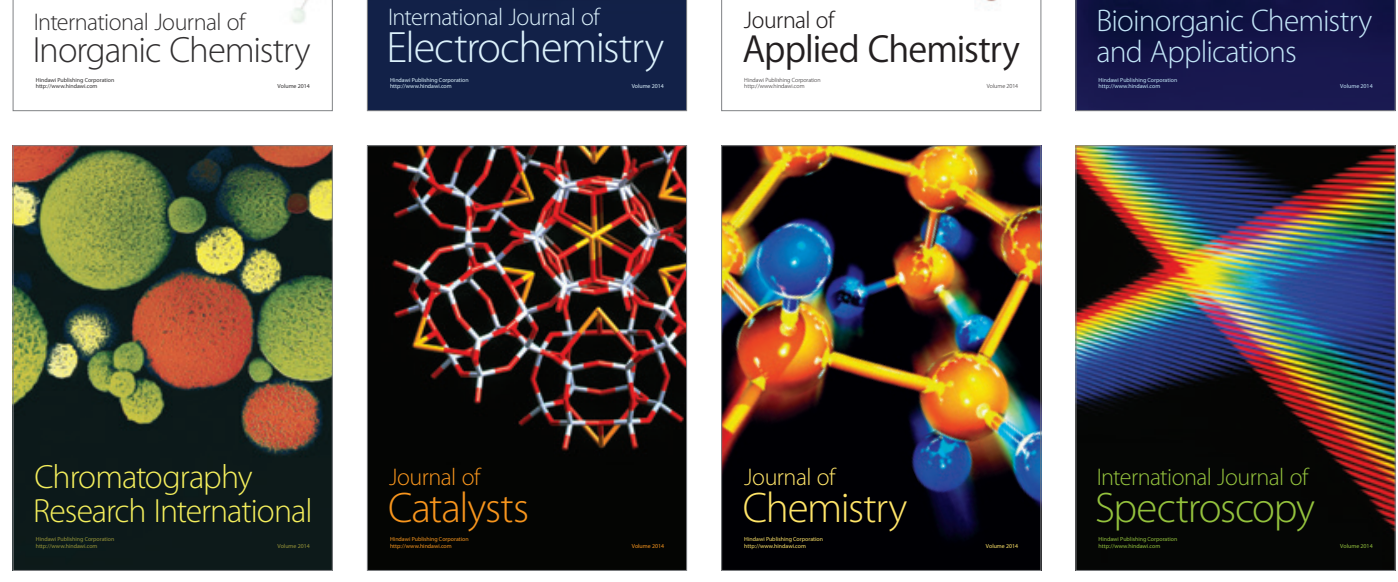